\title{
Equitable Access to Healthcare Services and Income Replacement for Cancer: Is Critical Illness Insurance a Help or a Hindrance?
}

\section{Accès équitable aux services de santé et remplacement de revenu dans les cas de cancer : l'assurance contre les maladies graves est-elle une aide ou une entrave?}

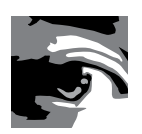

by CHRISTOPHER J. LONGO, MSC, PHD

Assistant Professor, Strategic Market Leadership and Health Services Management,

DeGroote School of Business

Member, Centre for Health Economics and Policy Analysis

McMaster University

Hamilton, ON

\begin{abstract}
Canada's publicly funded healthcare system ensures that medically necessary hospital and physician services are available without financial barriers, but not all communitybased care is covered. Consequently, many patients experience financial shocks (FS) related to community-based healthcare services not funded by government, and
\end{abstract}


perhaps also from lost income, a situation that may be difficult for patients to avoid. Critical illness insurance (CII) offers a patient-funded alternative to those who qualify and desire protection against FS, leaving those without CII exposed. The author discusses the benefits and limitations of CII to mitigate financially derived healthcare access inequities, using cancer as an example.

\section{Résumé}

Le système de santé canadien financé par les fonds publics assure que les services médicaux et d'hospitalisation nécessaires sont accessibles sans obstacles financiers, mais les services communautaires ne sont pas tous couverts. Par conséquent, plusieurs patients vivent un contrecoup financier lié à l'utilisation des services de santé communautaires qui ne sont pas financés par le gouvernement, ou lié à une perte de revenu; une situation que les patients peuvent parfois difficilement éviter. L'assurance contre les maladies graves offre une possibilité, financée par le patient, pour ceux qui y sont admissibles et souhaitent une protection, ce qui laisse les patients sans cette assurance susceptibles de vivre un contrecoup financier. L'auteur discute les avantages et les limites de l'assurance contre les maladies graves dans l'atténuation des inégalités d'accès financières face aux services de santé, en utilisant comme exemple le cas du cancer.

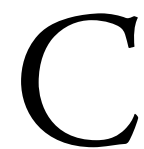

ANADA'S PUBLICLY FUNDED HEALTHCARE SYSTEM PROVIDES HOSPITAL AND physician services to all residents without financial costs in accordance with the Canada Health Act (CHA). However, government funding decisions for non-CHA healthcare services often result in exclusions, limits on service quantity, co-payments or deductibles. Additionally, services that are considered essential from a patient's perspective may be deemed non-essential by government, with these costs borne fully by patients and their families. Finally, many illnesses have impacts on patients' ability to work. Although Canadian health programs attempt to address issues related to equity of access without financial barriers, some aspects of care still raise financially based access issues. In other words, the current healthcare system does not fully address inequities based on the ability to pay. Although the resulting inequities may be much less significant than those seen among our American neighbours, they nonetheless still occur with some regularity. These issues surrounding equity of access are often presented as horizontal equity issues. Horizontal equity ensures that those with similar needs are treated similarly (Culyer 1995). The Canada Health Act addresses the issue of horizontal equity effectively for medically necessary hospital and physician care. However, there remain inequities in the access to many communitybased health services. 
This inequity is illustrated by the fact that some individuals experience financial shocks associated with illness while others do not. Financial shocks (FS) are defined as large financial expenditures that are both unexpected and beyond the financial means of those experiencing them. There are insurance products capable of addressing those FS precipitated by illness, namely critical illness insurance (CII). CII is a fixedreimbursement policy that pays a lump sum to the insured once he or she is diagnosed with a specific illness. The payout is conditional upon a physician's diagnosis and provided the insured survives 30 days beyond the diagnosis. The popularity of CII may be influenced by the fact that although the risk for most purchasers is relatively low, individuals are likely to exaggerate this risk for rare events, making CII appear more attractive (Viscusi 1990). Hence, CII demand is growing despite the fact that other forms of private health insurance are provided to the majority of working Canadians through their employers or individual purchases (Colombo and Tapay 2004). These insurance policies provide coverage for many of the services that fall outside the Canada Health Act or public funding, and include drug plans, hospital room upgrades, eye care, dental care and coverage for a variety of healthcare professional services delivered outside the hospital setting. However, even for those who have private healthcare benefits, issues with service limits, co-payments or deductibles can create inequities and result in a reduced consumption of healthcare services (Keeler 1992; Anis et al. 2005). Additionally, some working Canadians have no employer-sponsored health insurance; when they need these unfunded healthcare services, they must pay for them out of pocket, thereby generating FS (Applied Management 2000).

Illness carries with it not just medically related patient expenditures, but also has impacts on the ability of patients and their caregivers to attend work. Although many working Canadians have employer-funded supplemental disability insurance that will provide income replacement while recovering from an illness, these are typically optional employee benefits that are provided for a fee. Moreover, not all employers offer such benefits. Recent Canadian statistics suggest that short-term disability is provided to approximately $50 \%$ of the labour force and long-term disability to about $30 \%$, based on data from 1980 to 1996 (Campolieti and Lavis 2000). Hence, private insurance programs are capable of addressing both non-CHA health services and income loss, but there still remain patients for whom insurance coverage is incomplete or nonexistent. Some of these uninsured patients may be eligible for publicly funded income replacement, but in most cases this coverage constitutes only partial income replacement, and would not apply if work loss is sporadic. Thus, CII has the potential to cover patient costs beyond what is offered using both public and private mechanisms.

\section{The Case of Cancer}

Previous studies in the Canadian setting have shown that healthcare coverage in cancer 
is both inconsistent and incomplete (Menon et al. 2005; Longo et al. 2007; Aronson 2002). Additionally, in many cases cancer treatment results in a significant amount of lost income for both the patient and the patient's caregivers (Longo et al. 2006; Lauzier et al. 2008). Even for those with private healthcare insurance, co-payments for nonCHA healthcare services can become significant for cancer care, where the pharmaceutical therapies and healthcare professional usage often generate FS for patients and their families. Previous Canadian research has suggested that the aggregate of these cancer-related FS (non-coverage, co-payments, lost income) have been described by $20 \%$ of patients as a "significant or unmanageable burden" (Longo et al. 2006). Whether governments should take full responsibility for all health-related financial expenditures is certainly debatable (Wilson and Rosenberg 2004; Musgrove 1999). However, if we accept that one of the principal premises of publicly funded cancer care is to eliminate inequities based on ability to pay (Hutchison 2007), there is evidence that government policies have not been fully successful for cancer treatment. Cancer is also an interesting case to examine, as in most instances decisions to forgo treatment for financial reasons are likely to have implications on patients' health. Perhaps the risk of FS and its implications for access to treatment explains why Canadians are increasingly purchasing CII. Data show that in Canada, $70 \%$ of CII claims are for cancer, although coverage includes other illnesses (Munich Reinsurance 2006). The growth in these policies was in excess of 20\% per annum between 2000 and 2005 (Munich Reinsurance 2006), and was approaching 400,000 individually purchased policies by year-end 2005 .

\section{Critical Illness Insurance: Benefits}

Insurance products such as CII are a potentially useful mechanism to address FS. This is because there are no restrictions on how the funds may be used once a diagnosis is confirmed. A patient may therefore use the funds, for example, to purchase more inhome health services as a supplement beyond government coverage limits. In addition, patients may use the funds to obtain the most recent advances in technology that have not yet been funded through government programs, or to supplement income and allow themselves or a family member to take time freely from work without concern over the financial implications of this decision. It is even possible for patients to use the funds to take a needed vacation in a pleasant environment to aid in their recovery. In this regard, CII has a direct impact on quality of life by reducing financial stresses for patients and their family members during what may well be their most trying times.

Although the reasons for the popularity of CII products in Canada have not been fully researched, some of the rationales mentioned above may be possible explanations. Further research in this area is needed to clarify the demand for these types of insurance products. It is safe to say, however, that the market for CII exists only if there is a public perception that a diagnosis of cancer (or other devastating illnesses covered 
under these policies, such as heart attack and stroke) carries with it a risk of FS. A recent examination of CII purchasing behaviour concludes that the motivation is likely a combination of coverage for cancer expenditures, lost income and a state-utility transfer to compensate for being sick (Longo and Grignon 2009). Thus, for some segment of the population, there is a suggestion that private health insurance products such as CII are a prudent way to manage these potential FS.

\section{Critical Illness Insurance: Limitations}

An important consideration in identifying program solutions for illness-related FS is ensuring that all citizens have equitable access to these programs. To be effective, at least in terms of equity goals, CII needs to provide coverage to all populations, including those most in need. Interestingly, individuals who are most likely to have high expenditures or have a higher risk of expenditures are those with limited private health coverage (Roetzheim et al. 1999), lower incomes (MacKillop et al. 2000) and existing co-morbidities (Gonzales et al. 2001). These same populations are also more likely to have high out-of-pocket costs compared to those at low risk. Typical premiums for these CII policies are unaffordable by individuals in the lowest income categories. This affordability assumption is based on the premise that more than $4.5 \%$ of gross income would be deemed unaffordable, a marker typically used for a drug expenditure means test (Ontario uses $4.5 \%$ and Manitoba uses 3.5\% of gross family income). A working paper by Longo and Grignon (2009) suggests that more than 20\% of the Canadian population would be unable to afford the CII premiums needed for illness-related expenditure coverage (cancer care services and compensation for lost income) related to cancer. Additionally, insurers exclude many patients who are deemed high risk, either because of pre-existing conditions, family history of covered diseases, or previous health events. Consequently, up to $30 \%$ of applicants are denied coverage, or are offered coverage with specific exclusions such as a cancer diagnosis (Munich Reinsurance 2006).

The result is that although CII has the potential to address the FS that many Canadians with cancer may experience, there is evidence that many of those individuals most likely to benefit would in fact be unable to obtain, or unable to afford, the necessary coverage. Hence, those individuals who do actually receive CII coverage may prove to be those who least need it.

\section{Government Policies Related to Cancer Care}

Current health policies ensure that much of the essential care for cancer is covered through the public purse, including physician services, hospitalization and drug therapies delivered in hospital. However, the current funding strategies employed in most provinces almost guarantee that some of the financial burden will be borne by patients 
and their families, and is especially pronounced in those with inadequate insurance. It is likely that most Canadians would not expect all cancer-related costs to be covered, but they might expect that health policies would ensure they are not expected to manage FS while managing their illness. Governments should be aware of these FS in cancer care and the burden they place on patients and their families. Governments should consider adopting policies that minimize or mitigate these FS for those most in need. The evidence in cancer suggests that problems can occur when policy strategies rely too much on private sector solutions for non-CHA services. These problems stem from private sector interests in maximizing profits rather than ensuring equitable access. Private sector profitability is achieved partly by excluding those at highest risk ("cream skimming"), leaving the excluded individuals with no protection from FS, especially those who are uninsured or underinsured.

\section{Conclusion}

CII can offer coverage not provided by public and private health insurance and does ensure that those who are willing and able to purchase it are in a better position to weather FS; but many of those most in need are either unable to obtain or afford the coverage and so are no better off. In fact, it can be argued that these insurance offerings provide more latitude for governments to encourage private sector solutions for non-CHA healthcare services. Recent evidence of this is illustrated by the opening of private infusion clinics beginning in 2005, and the growing number of unfunded cancer drugs in recent years (Cancer Advocacy Coalition of Canada 2007). A potential concern is that the resulting inequity may in fact become worse when these private sector solutions are utilized. It is also not hard to imagine that as more targeted drugs enter the market with premium pricing, the demand for products like CII will only increase, as will the risk of FS. Governments interested in ensuring equitable access for all citizens would do well to pay attention to the implications of private financing of non-CHA healthcare services for cancer treatment.

Correspondence may be directed to: Christopher J. Longo, Assistant Professor, Strategic Market Leadership and Health Services Management, DeGroote School of Business, McMaster University, 1280 Main Street W. (DSB-210), Hamilton, ON L8S 4M4; tel.: 905-525-9140 ext. 23896; fax: 905-521-8995; e-mail: cjlongo@mcmaster.ca.

\section{REFERENCES}

Anis, A.H., D.P. Guh, D. Lacaille, C.A. Marra, A.A. Rashidi, X. Li and J.M. Esdaile. 2005."When Patients Have to Pay a Share of Drug Costs: Effects on Frequency of Physician Visits, Hospital Admissions and Filling of Prescriptions." Canadian Medical Association Journal 173(11): 1335-40. Applied Management. 2000. Canadians' Access to Insurance for Prescription Medications: Vol. 2. The Uninsured and the Underinsured. Ottawa: Health Canada. 
Aronson, J. 2002. "Elderly People's Accounts of Home Care Rationing: Missing Voices in LongTerm Care Policy Debates." Ageing and Society 22: 399-418.

Campolieti, M. and J.N. Lavis. 2000.“Disability Expenditures in Canada, 1970-1996: Trends, Reform Efforts and a Path for the Future." Canadian Public Policy 26(2): 241-64.

Cancer Advocacy Coalition of Canada. 2008. Report Card on Cancer in Canada: 2007. Part 3: Cancer Drug Access. Toronto: Author.

Colombo, F. and N. Tapay. 2004. "Private Health Insurance in OECD Countries: The Benefits and Costs for Individuals and Health Systems." OECD Health Working Papers 2004, No. 15. Doi: $10.1787 / 527211067757$.

Culyer, A.J. 1995. "Need: The Idea Won't Do - But We Still Need It." Social Science and Medicine 40(6): 727-30.

Gonzales, E.C., R.G. Roetzeim, J.M. Ferrante and R. Campbell. 2001. "Predictors of Proximal vs. Distal Colorectal Cancers." Diseases of the Colon and Rectum 44: 251-58.

Hutchison, B. 2007. "Disparities in Healthcare Access and Use: Yackety-Yack, Yackety-Yack." Healthcare Policy 3(2): 10-18.

Keeler, E.B. 1992. "Effects of Cost Sharing on Use of Medical Services and Health." Journal of Medical Practice Management 8(1): 11-15.

Lauzier, S., E. Mausell, M. Drolet, D. Coyle, N. Herbert-Croteau, J. Brisson, B. Masse, B. Abdous, A. Robidoux and J. Robert. 2008. "Wage Losses in the Year After Breast Cancer: Extent and Determinants among Canadian Women." Journal of National Cancer Institute 100: 321-32.

Longo, C.J., R. Deber, M. Fitch and A.P. Williams. 2006. "Financial and Family Burden Associated with Cancer Treatment in Ontario." Supportive Care in Cancer 14: 1077-85.

Longo, C.J., R. Deber, M. Fitch, A.P. Williams and D. DeSouza. 2007. "An Examination of Cancer Patients' Monthly 'Out-of-Pocket' Costs in Ontario." European Journal of Cancer Care 16: 500-07.

Longo, C.J. and M. Grignon. 2009. “The Value of Fixed-Reimbursement Healthcare Insurance. Evidence from Cancer Patients in Ontario, Canada." Working Paper Number 09-03. Hamilton, ON: Centre for Health Economics and Policy Analysis, McMaster University.

MacKillop, W.J., J. Zhang-Salomons, C.J. Boyd and P.A. Groome. 2000. "Associations between Community Income and Cancer Incidence in Canada and the United States." Cancer 89: 901-12.

Menon, D., T. Stafinski and G. Stuart. 2005. “Access to Drugs for Cancer. Does Where You Live Matter?" Canadian Journal of Public Health 96(6): 454-58.

Munich Reinsurance Company Canada. 2006. Munich Reinsurance Critical Illness Survey 2006. Toronto: Author.

Musgrove, P. 1999. "Public Spending on Health Care: How Are Different Criteria Related?" Health Policy 47: 207-23.

Roetzheim, R.G., N. Pal, C. Tennant, L. Voti, J.Z. Ayanian, A. Schwabe and J.P. Krischer. 1999. "Effects of Health Insurance and Race on Early Detection of Cancer" Journal of the National Cancer Institute 91(16): 1409-15.

Viscusi, W.K. 1990. "Sources of Inconsistency in Societal Responses to Health Risks." American Economic Review 80(2): 257-61.

Wilson, K. and M.W. Rosenberg. 2004. "Accessibility and the Canadian Health Care System: Squaring Perceptions and Realities." Health Policy 67: 137-48. 